DOI: 10.2478/ausp-2019-0033

\title{
Border Crossing of an Educational Policy Towards an Analytical Framework to Study Educational Transfer
}

\author{
Zsófia HANGYÁL \\ $\mathrm{PhD}$, Institute of International and Comparative Education (IICE) \\ Beijing Normal University, Faculty of Education \\ Tempus Public Foundation, Budapest, Hungary \\ E-mail: hangyal.zsofi@gmail.com
}

\begin{abstract}
This paper aims to better understand the process of educational transfer from Western countries to developing ones by proposing an analytical framework. The framework, besides counting for the major challenges of a specific educational transfer, also proposes to analyse some of the factors of different cultural-educational contexts that may help or burden institutional innovation. The framework had been tested by case study research focusing on the educational transfer of liberal arts colleges from the Netherlands to China. In the cities of Chongqing and Taigu, two undergraduate colleges grounded the case of investigation in order to study the experiential perceptions of stakeholders shortly after the implementation of liberal arts programmes (2012). Meanwhile, the data revealed different interest groups and particular institutional constrains, and the analytical framework greatly helped to understand and illustrate issues of compatibility, acceptance, mobilization of different stakeholders, and strategies for both individual and institutional agency. As the research contributed to a dissertation essay completed in 2016 at Beijing Normal University, the present study's objective is to highlight the importance of analytical framework(s) in the process of interpreting data into research findings.
\end{abstract}

Keywords: analytical framework, educational transfer, internationalization, cultural context, China

\section{Introduction}

Educational transfer (often called educational policy borrowing) focuses on extracting educational models that are perceived as effective from other systems (Steiner-Khamsi 2004: 1). Within the ongoing processes of globalization and internationalization, international models of (higher) education have newly become objects of import and export. However, it is important to note that the 
act of borrowing is not copying; it draws the attention to processes of local adaptation, modification, and resistance to global forces in education (ibid.). The extent of modification can result in a rather different educational model that barely resembles the borrowed one; on the other hand, this fact does not predict or determine the success of local adaptation. Due to processes of localization, moving policies of higher education draw the attention towards differing cultural, educational contexts and notions of identity across borders - the necessity of interpreting such complex issues required the development of frameworks that could help to understand the impact of transfer both at the individual and institutional level (see the studies of Phillips and Ochs 2004, McDonald 2012, Forestier-Crossley 2014).

The framework for this study was developed focusing on the extensive research of educational borrowing and institutional logics (as defined primarily by Thornton, Ocasio, and Lounsbury, 2012) and was applied for data analyses in the doctoral dissertation completed in 2016: Educational Transfer of Liberal Arts Education: Case Studies from Chongqing and Taigu (China). The primary purpose of the doctoral research was (1) to discover local actors' (faculty, students, and other stakeholders) efforts in interpreting liberal arts education with particular attention to meanings, curriculum, pedagogy, and institutional strategies (2) and to explore whether and in what ways these individual claims conflict with the current institutional strategies. Some of the key findings revealed modified, "culturallyabsorbed" meanings of liberal arts education, unstable curriculum structure, and conflicting educational concepts within the faculty (Hangyal-Jun 2017). The present study aims at highlighting the importance of analytical framework in interpreting the data and developing research findings; thus, it presents some of the major findings regarding the implementation of liberal arts programmes in China.

China's need for a maintained economic growth has initiated a diversification of its market. Its shift from a labour-intensive industrial society towards a knowledgebased economy has been spurring the drive for innovation and the development of expertise, resulting in continuous efforts towards improving the Chinese higher education system (see the extensive work on the history of higher education in China by Gu, Li, and Wang 2009). In the sequence of the societal and demographic challenges China has faced as well as the increased number of Chinese young people studying abroad, the Chinese higher education system has embarked on a process of rapid massification, internationalization, and transformation (Kai 2005). Besides higher education policies that targeted attracting more and more foreign students and experts (for example, projects 985 and 211), ${ }^{1}$ educational

1 The Chinese Ministry of Education launched Project 211 to give increased financial support to 100 selected universities. Project 985 provided even greater funding to 43 universities in order to help them develop into "world-class universities" by 1998. These projects were focused on complex institutional development strategies. 
borrowing from foreign countries has caught greater attention in the recent years. In particular, the tendency of reforming undergraduate education that manifested through the introduction of a broad-based curricular approach with general courses to enhance students' all-round literacy was remarkable (Wang 2014). For this reason, a more "humanist" approach in higher education, the so-called Rén wén jiào yù (the closest interpretation of liberal arts education) was implemented in China at many universities such as Peking University, Zhejiang University, Beijing Normal University, and Nanjing University (ibid.). Given the fact that liberal arts programmes have become increasingly popular in the Netherlands where seven undergraduate liberal arts colleges were founded in the last decade thanks to the extensive work of higher educational expert Hans Adriaansens -, China imported this specific educational model in the cities of Chongqing and Taigu (Mykoff 2012). This specific model of the Dutch liberal arts programmes - which partly modifies the original US model of liberal arts programmes by placing more emphasis on student-centred classroom management and interactive pedagogy - was also implemented in other countries - for example, in Germany and Slovakia (Eschenbruch 2014). Due to the novelty of the Dutch-style liberal arts programmes in China, the transferred model had to be adapted to different educational and socio-cultural traditions. As a result, the implementation process led to several challenges both at the institutional and individual level: how to balance Chinese and Western educational traditions, pedagogical approaches? What kind of institutional strategies could be effective in the localization of a foreign educational model?

The present study intends to present an analytical framework that could deepen our understanding on educational transfer and its contextual burdens. The paper consists of two major parts: the alignment of institutional logics and educational transfer theories into an analytical framework and its application to the empirical case study of liberal arts programmes in China, in the cities of Chongqing and Taigu.

\section{Background - Liberal arts education and colleges}

The terms of liberal arts and general education are often used interchangeably, especially in the United States (Boyer 1987). As it was mentioned before, general education has been present in the Chinese higher education over the past 20 years: broad-based curriculum was implemented into the undergraduate studies at several research universities (Wang 2014). However, the definition of liberal arts education extends the concept of general education (breadth component of the curriculum): it emphasizes a student-centred, dialectical education ("breadth and depth") that seeks to develop a more effective, interactive classroom 
management where the student is not a passive recipient of knowledge but an active participant in a common search (Brann 2000). Examining the model of liberal arts college in the Netherlands, Eschenbruch (2014) described the institution's core concept with the learning relationships and commitment between students and professors (relational framework), with the curricular framework that implements these learning relationships into the curriculum, and with the institutional framework that supports and generates the coherence of the above mentioned two frameworks. There is a flexible curriculum design that ensures the possibility of combining courses from different scientific areas; however, the three major departments are Social Sciences, Sciences, and Arts and Humanities. Based on the course offerings, each student has to create an individual study plan at the beginning of their studies. There are three levels of the courses: introductory, intermediate, and advanced level. Additional features of the Dutch liberal arts programmes are: small class sizes (less than 25 students in each class), academic excellence, focus on undergraduate research, interactive classes, loosely defined curriculum and individual study plans, personal tutoring, and residential living in campus (Eschenbruch 2014).

As the pilot visits for the dissertation research revealed, the undergraduate colleges in Taigu and Chongqing are the results of a bottom-up educational transfer (initiated by a Chinese businessman), and the educational concept was modelled on the Dutch Roosevelt University College in Middelburg. Dutch educational experts helped the implementation process with various visits and trainings. The private colleges in Chongqing and Taigu are rather small-scale institutions as far as their academic capacity is concerned: staff amounts to 25-30 teachers (including administrators), and 100-150 students enrol every year. Besides the popularity of implementing general elective courses into the curricula of many Chinese universities (see Wang's study on the Yuanpei College, 2014), these colleges were among the first universities in China to implement liberal arts programmes with major curricular and pedagogical reforms at the classroom level. The curriculum offers a wide range of courses and ensures a flexible design so the students can combine courses from different scientific departments. Regarding pedagogy and classroom activities, teachers are encouraged to use a more student-centred teaching style, one that focuses on interactive classroom activities that could possibly foster students' critical thinking, communication skills, and social responsibility. Further novelty features are the tutoring system, which assigns an academic advisor to each student, and the class structure, which is made up of relatively small groups (20-25 students per class) compared to other Chinese undergraduate colleges. To ensure a more international environment for the students, the management of the college has built up study exchange projects with foreign universities and seeks to hire teaching staff who has studied abroad. 


\section{Analytical framework from the perspectives of institutional logics}

The analytical framework is a useful tool that can improve the validity of research findings by enhancing objectivity with a strong theoretical background. When it comes to educational transfer from Western countries into developing ones, the differences in the educational traditions and policies also need to be considered carefully. Forestier and Crossley (2014), analysing a two-way educational policy borrowing between England and Hong Kong, had developed a comparative chart that emphasizes the major differences of the progressive Western education schemes and the Confucian heritage model that characterizes most of the East Asian countries' educational traditions. As the pilot visits in the colleges showed, implementing liberal arts colleges in China did not bring either the integration of the Western progressive model or leaving behind the traditional educational heritage; it rather created an "interpretation-adoption" process that needed to happen both at individual and institutional level. To make an example, teachers that had received teacher training according to the Confucian heritage-educational model, placing emphasis mainly on didactic methods (authoritative teacher, content-oriented learning, memorization based on repetition), were required to revise and update their teaching methods and classroom design, introducing more student-centred, interactive methods in the spirit of liberal arts programmes. To what extent have they changed their ideas and attitudes, accepted or neglected changes? How did teachers deal personally with creating an integrated and particular teaching model of liberal arts? At the institutional level, as the preliminary study visit revealed, the biggest challenge was to promote the features of liberal arts education (whole person development, student-centred and collaborative learning) in a competition-based, examinationand result-oriented educational context. How could the institution motivate the faculty to develop any need within for a change? To what extent could the institutional strategy combine the borrowed and local educational traditions, elements? The below presented analytical framework aimed to construct a strong theoretical background that could help to answer these questions and consider the contextual issues that could burden the implementation of liberal arts programmes. 


\section{The Netherlands}

Progressive Western model

Progressivism/cognitive pluralism

Whole person development, skill learning, creativity and critical thinking

Project learning, collaborative learning, assessment for learning

Collaborative, constructivist, understanding,

Flexible design, subjects at 3 levels (beginner, intermediate, advanced)

Project assignment/research paper

Research oriented BA and BSc programmes

Progressive: understanding, collaborative, constructivist

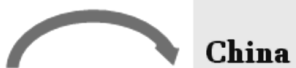

\section{Confucian heritage model}

IDEOLOGY Confucian heritage/ academic rationalism

LEARNING Self-perfection, respect, discipline, CULTURE humility, competition

PEDAGOGY Didactic teaching (teacher-centered, content oriented, lecturing)

APPROACHES Memorisation, repetition, competitive, rote learning

CURRICULUM Subjects designed according to availability, courses are introductory

ASSESSMENT Competitive examination

POLICIES Quality assessment of undergraduate education (2002) updating traditional teaching methods

\section{How are these values interpreted within institutional strategies?}
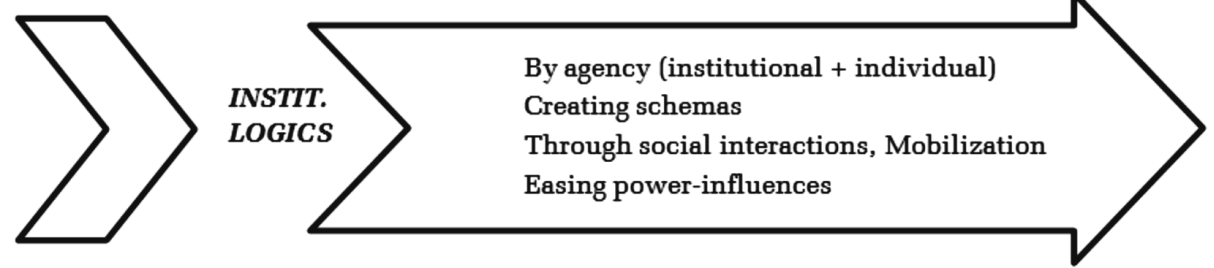

Figure 1. Differing educational contexts and institutional logics to help the transmission. Adapted from Forestier and Crossley (2014) and Thornton, Ocasio, and Lounsbury (2012)

Institutional logics, principally the relevant research by Thornton, Ocasio, and Lounsbury (2012), aimed at enhancing our understanding of institutional transition processes linked to reforms and innovative policies. Its concepts focus on various strategies that could help policy adaptations and push forward the implementation process. How has the concepts of institutional logics become relevant for my study? Firstly, it focuses on institutional change and on the interactions between organization, individuals, culture, and society; therefore, a detailed contextual analysis could possibly enrich the data and findings. Furthermore, institutional logics can also highlight the cross-level effects and 
some of the casual mechanisms between institutional strategies and individuals (Thornton-Ocasio-Lounsbury 2012: 32). Secondly, the institutional logic model accounts for individual cognition. Teachers' and students' sense-making of liberal arts' programmes is a complex issue because it guides the attention far beyond institutional mechanisms, towards fields that can be hardly "theorized" - to individual perception, fields of psychology, and diversity. As Swidler (1986: 275) pointed out, "people may share common aspirations, while remaining profoundly different in the way their culture organizes their overall pattern of behaviour". So to say, the institutional logics model combines both material (structures and practices) and symbolic elements (ideation and meaning). Regarding the symbolic elements, it is important to note that these elements are not stable, and their meanings and interconnectedness can change overtime.

In order to interpret the data and consider them as research findings, the dissertation research involved several indicators based on institutional logics. These trajectories were selected due to their influencing role on institutional and behavioural change. Most importantly, both individual and institutional agency were examined: how did the institution promote particular identities, goals, and schemas? Regarding individual agency, what kind of actions and behaviours had been guided by self-interest? What particular social identities (e.g. profession, age cohort, political party, and ethnicity) were significant in determining the level and depth of learning about liberal arts programmes? (Thornton-OcasioLounsbury 2012: 92). The analytical framework also involved the concept of schemas (the ways how people understand, remember, and act upon complex information; how they resolve ambiguities, guide evaluation, and make choices) and the importance of social interactions and their roles in transmitting cognitive meanings (2012: 88) on the institutional side, the model considered mobilization; institutional strategies that facilitate the development of alternative behaviours, however, are actions that seek to reach collective goals considering individual differences of commitment and embeddedness. Both individual and institutional agency are dependent on different power-influences such as the role of family, religion, politics, culture, and educational traditions (id. 78).

\section{Methodology}

The methodology built upon constructivist research paradigm: the present study relies on participants' views on the phenomenon of liberal arts programmes and colleges in China (Creswell 2003). The case study research design involved qualitative methods and was focusing on two major case studies in the colleges of Chongqing and Taigu. Primary data were collected by semi-structured interviews, non-participant observations (in- and out-of-classroom settings), field notes, and 
memos. In total, 31 interviews were conducted in Chongqing and 28 in Taigu (in English and Chinese language) with college students, teachers, faculty members, administrators, and other stakeholders of the colleges. The sampling was purposive in the sense that specific aspects of liberal arts education were examined (meanings and definition of liberal arts education, curriculum, pedagogy, and institutional strategies), and the interview participants had to be closely aligned with the Chinese liberal arts colleges mentioned above. The conceptual framework drew upon Philips and Ochs's (2004) studies on educational transfer analyses and McDonald's (2012) research of the mentioned framework. However, the framework was modified in order to have a better focus on the stage of implementation and on specific aspects of the educational transfer examined through the interviews (for the conceptual framework, see Hangyal-Teng 2017).

The data analyses followed Mayring's approach (2000) on qualitative content analyses, which is a widely recognized method for case study research design (Kohlbacher 2005). The strength of this method is that it considers the given context as a "latent content" that has to be considered in the process of category development (ibid.). The categories were organized under the subcategories of the semi-structured interviews' and the conceptual framework's categories and helped the consistency of the interpretation and content analyses process (meanings and definition of liberal arts education, curriculum, pedagogy, and institutional strategies). In order to ensure the validity and reliability of the research, the study involved several triangulation methods: (1) methodological triangulation for data collection, (2) reflexive approach (Luttrell 2010), and (3) theory triangulation introducing analytical perspectives (Denzin-Lincoln 2000). The analytical frameworks that helped to interpret the data were the composite processes of educational borrowing (Phillips-Ochs 2004), institutional logics by Thornton, Ocasio, and Lounsbury (2012), and theories of differing educational contexts (Forestier-Crossley 2014).

\section{Some of the research findings in respect to the analytical framework}

\section{General situation of the Chinese colleges - Individual and institutional agency}

Implementing liberal arts college and education took place in the period of March-August 2012; however, the transfer at that time had rather aimed at getting the "hardware" ready - the facilities of the colleges (own buildings and classrooms). There were no trained workforce, teachers, administrators, or a dean for the colleges. It had been also expressed that the first-grade students - enrolled 
in September 2013 - had no selection criteria to enter the college; it was just about "getting live bodies" - as the dean mentioned later on. In Taigu, it was the duty of the ex-vice-dean to create the curriculum based on the example of the Dutch Roosevelt College. However, the first curriculum was rather a direct translation from the English one into Chinese language, without considering the suitability for the local context; later on, the vice-dean had to rewrite it six times in order to suit the teaching staff's capacity and the Chinese credit requirements better. Having a teacher shortage also led to unavailable courses and a lack of balance within the departments of Social Sciences, Humanities and Sciences. At this time, the future dean had various visits at both colleges; the structure of majors and the curriculum were only templates to follow, without considering their local suitability (a copy-and-paste stage of implementation): the teachers had no idea about liberal arts education nor how differently they were supposed to teach their courses.

As more interviewees expressed, the real adaptation of the transferred model had started with the arrival of a foreign dean at both colleges, in late March 2013. The dean was a catalyst of many changes at the level of both institutional and individual agency: editing the curriculum to fit more the Chinese higher educational context and credit requirements, organizing teacher trainings, starting micro-teaching for teacher's peer-learning, peer-evaluation for teachers by attending each other's classes. Regarding teaching issues, the dean was one of the leading actors that created liberal arts programmes for teachers by revising the course content and support them in their own learning process. How to create a course plan that is interlaced with other subjects' topics? How to improve classroom management, involving discussions and student work? It could be generally seen that throughout the initial stages of adaptation the institutions had somewhat arranged the transfer but rather according to the Chinese educational ideas and context (curriculum, credit settings, or years of study), leaving behind some of the original features of the transferred Dutch model (for example, the flexible curriculum design, different levels of course offerings).

In the years 2014-2015, a phase of general stagnation manifested at both the individual and institutional level in the life of the colleges also due to several unfortunate external factors such as teacher shortage and decreasing financial funds. As the interviews showed, attracting proper, well-trained teachers was a difficult issue as the colleges are not located in big Chinese cities, and they do not belong to public universities; Chinese teachers prefer to work at public universities because of better welfare, ensured job security, and better societal recognition. The teacher shortage and the frequent changes within the faculty made the institutional planning process problematic. How to have a long-term plan on developing the college in a systematic way? Furthermore, the initial funds that ensured to facilitate the implementation had slowly decreased. The 
lack of teacher incentives was also mentioned throughout the interviews: as an interviewee underlined, public universities generally support supervising students or ensure some funds for extracurricular activities such as going to theatre or museums. It was expressed that the actual quota for supervising students in Chongqing was not enough to organize certain activities outside the college. At the individual level, more teachers talked about a carrier bottleneck; they expressed that they could not get any cognitive reinforcement at work or promotion. They were also concerned with limited possibilities of self-progress; they could hardly get any feedback about their work or the results of new teaching methods. The institutional management should have created some additional incentives or performance-based rewards for excellent teachers.

\section{Liberal arts meanings in the Chinese context - Ideology and learning culture}

The accounts of various faculty members were similar as far as the concepts and meanings of liberal arts programmes. The definition of liberal arts education showed certain interconnectedness with the society, different social roles, and moral values. Teacher interviewees often expressed that the true meaning of liberal arts programme is to educate students "to be a good person in society". However, regarding this question, different moral values were explained by teachers - for example, "usefulness for the society", "behaving properly and having manners", or "following the rules". Especially accounts from Taigu showed a significant pattern of mentioning the importance of rules. Such moral values are deeply rooted in traditional Chinese Confucianism and in societal expectations about what "a good education" should stand for. Traditionally, the most important role of a teacher in China is to cultivate morality in students (Wang 2014). For this reason, as the data of qualitative interviews summed up, the definition of liberal arts education in Chongqing and Taigu rather represented culturally and contextually absorbed meanings. Semantically, in Chinese language, liberal arts education is often translated as Ren wen jiao yu, which could be best interpreted as 'education in the humanities' but not necessarily for a Chinese person. The concept of Ren, as many Chinese words, refers to thousands of meanings historically (Stefon 2016). According to Confucianism, Ren is one of the most idealistic virtues that means humaneness, being altruistic, responsibility for caring for others, therefore ideals with moral and ethical significance (ibid.). Analysing the meanings that interview participants developed, it can be assumed that some people understood literally the meaning of liberal arts education (Ren wen jiao yu) and aligned some of the cultural-moral meanings into their personal interpretations. Regarding definition and ideology, the interviews showed that only a few percentage of the overall respondents referred to creativity and critical thinking as part of liberal 
arts education. This fact draws the attention to the analytical framework and to the Western progressive model of learning culture that puts emphasis on such learning skills; meanwhile, in the Chinese context of liberal colleges, values of creativity and critical thinking were deemed less important.

\section{Pedagogy and learning approaches}

Cultural alignments came forward in interpreting liberal arts pedagogies and classroom management too: according to the interviews, teachers, despite understanding the aims of liberal arts education, cannot teach completely in line with its principles because their mindsets are fundamentally rooted in the traditional way of Chinese teacher education. The analytical framework greatly helped to interpret the data by comparing the differences of the didactic teaching (Chinese model) and the progressive teaching model (the Netherlands). While the Chinese educational context emphasizes teacher-centred, content-oriented learning based on memorization and repetition, the progressive Western model supports project learning, collaborative learning in group settings, individual and group assessments (Forestier-Crossley 2014). Implementing collaborative and more interactive pedagogy - as the classroom observation also proved during data collection - was a complex challenge in Chongqing and Taigu as well. According to the Chinese educational system and traditions, teachers exert absolute authority in their classrooms and represent the most important source of knowledge (see Cheng's (2000) theory on the Chinese culture of learning; Xiao 2006). As Wang (2014) approached the topic in her study on the Yuanpei College in Beijing, there is seldom any group discussion led by students during classes or interaction between teacher and students. These conceptions of frontal learning, as many interviews showed, are deeply rooted both in teachers' and students' educational patterns. Most of the teacher respondents stated that due to lack of experience in classroom management they would need more professional training to implement new teaching methods. Based on the data, skill development (collaborative skills in particular) should be enhanced for both teachers and students. However, the data was not always homogeneous regarding teacher-student interactions in the classroom, especially among faculty members' responses; some of the accounts showed variations in embeddedness regarding the practical application of liberal arts programmes and pedagogies. Some teachers, as the classroom observation proved too, involve students into questioning and discussing classroom topics, making the course more interactive and student-centred. At individual level, the teachers of both colleges were at different stages of their own teaching-learning practice and involvement in liberal arts programmes - somewhere "from knowing nothing about this education mode to know something", and towards "I might do it much better in the future". Teachers are eager to change and shift their teaching 
methods towards more interactive, student-centred pedagogies. According to the data, most of them had already made significant progresses. As it was mentioned above, teacher trainings, micro-teaching sessions organized by the dean - thus, continuous interactions between the teachers - helped professional development (examples of institutional and individual agency).

\section{Curriculum}

The curriculum plan that the colleges implemented failed to satisfy the needs of many students according to the data. One of the main problems is teacher shortage: the courses were created and designed according to the available teachers without considering the demands of students or the original standards of the Dutch liberal arts curriculum (courses were offered in three major departments of Science, Social Sciences and Humanities). Currently, the teachers are mainly specialized in Social Sciences and Humanities rather than Natural Sciences in Chongqing and Taigu, and so the course offerings fail to meet every student's needs. Due to teacher shortage, the college students in Chongqing have to attend some courses at the main campus of the university; and most of these courses involve different teaching standards that are far from the liberal arts programmes' interactive, student-centred methods (lectures are given to 100-150 students). The curriculum is a good example of how the requirements of liberal arts education conflict with the college's current capacities. As it was also expressed by faculty respondents, the curriculum is still unbalanced and inconsistent, and there is no systematic understanding of the reasons for setting up the present framework; as a teacher spelled out, "things are just random". On the other hand, comparing the course offerings of the Chinese and Dutch liberal arts colleges, courses are only introductory and general in both Chongqing and Taigu, missing the modules of different levels that could build up on each other and ensure a deeper understanding of a given subject.

\section{Conclusions}

The analytical framework highlighted most of the reasons behind the suitability and adaptability of a foreign educational model transferred to China from the Netherlands. In the case of moving policies, it is important to consider the cultural and educational context of the recipient country, which in the given case is strongly rooted in the Confucian heritage model. Understanding Chinese academic traditions and pedagogies that focus on didactic teaching, interpreting faculty's difficulties in adjusting their teaching methods towards a more interactive, student-centred teaching and learning made more sense to the results 
of the data. The institutional logics shed light on processes of implementing a foreign policy both at individual and institutional level and highlighted the most important issues to be addressed by the administration of the colleges. Besides understanding how the transfer evolves and what the strengths and weaknesses of a transnational educational transfer are, it is also important to improve the institutional strategies against limited resources and teacher shortage. A limitation of the present study is that it has only shown the Chinese liberal arts education phenomenon in a specific period (2015-2016) when the research was completed, and the findings were based on two case studies. How the colleges will evolve regarding institutional strategies requires future investigation.

\section{References}

Baldwin, T.-Ford, J. 1998. Transfer of training: A meta-analytic review. Journal of Management 36(4): 1065-1105.

Boyer, E. L. 1987. College: The undergraduate experience in America. New York: Harper \& Row.

Brann, E. T. H. 2000. Eight theses on liberal education. (Retrieved on: 05/10/2015, from: http://faculty.pepperdine.edu/mgose/GBQuarterly/winter00/brann.html).

Cheng, X. T. 2000. Culture of learning and ELT in China. Teaching English in China 23(1): 47-48.

Coxon, E.-Nabobo, U. 2003. Preface. In: E. Coxon-A. Taufe'ulungaki (eds), Global/local intersections. Researching the delivery of aid to Pacific education. Auckland: Research Unit for Pacific Education, Auckland University.

Creswell, J. W. 2003. Research design: Qualitative, quantitative, and mixed methods approaches. ( $2^{\text {nd }}$ ed.). Thousand Oaks: Sage.

Davila, J. R.-Keirns, J. L. 1994. The effect of co-designing on educational transfer between cultures. In: ETR\&D 42: 89(4): 89-100.

Denzin, N. K.-Lincoln, Y. S. 2000. Handbook of qualitative research. Thousand Oaks: Sage.

Eschenbruch, N. 2014. Liberal arts college as an academic, social and experiential space. Speech presented at ACA Conference "Improving Undergraduate Education in Europe: Liberal Arts Colleges” (9/10/2014).

Forestier, K.-Crossley, M. 2014. International education policy transfer Borrowing both ways: The Hong Kong and England experience. Compare: A Journal of Comparative and International Education 45: 664-685.

$\mathrm{Gu}$, Jianmin Li-Xueping Wang, Lihua. 2009. Higher education in China. Education in China Series. Zhejiang: Zhejiang University Press. 
Hangyal, Zs.-Teng, J. 2018. Educational transfer of liberal arts education into China: A case study from Chongqing. International Journal of Research Studies in Education 7(1): 41-53. Consortia Academia Publishing.

Hawkins, John N. 1984. Educational exchanges and the transformation of higher education in the People's Republic of China. In: Elinore G. Barber-Philip G. Altbach-Robert G. Meyers (eds), Bridges to knowledge: Foreign students in comparative perspective. Chicago: University of Chicago Press. 19-32.

Hayhoe, R. 1986. Penetration or mutuality? China's educational cooperation with Europe, Japan and North America. Comparative Education Review 30(4): 532559.

Kai, Jiang. 2005. The centre-periphery model and cross-national educational transfer: The influence of the US on teaching reform in China's universities. Asia Pacific Journal of Education 25(2): 227-239.

Kohlbacher, Florian 2005. The use of qualitative content analysis in case study research. Forum Qualitative Sozialforschung / Forum: Qualitative Social Research 7(1): art. 21. http://nbn-resolving.de/urn:nbn:de:0114-fqs0601211.

Levine, A. 1978. Handbook on undergraduate curriculum. San Francisco: JosseyBass.

Luttrell, W. 2010. Qualitative educational research: Readings in reflexive methodology and transformative practice. New York: Routledge.

Marton, F. 1986. Phenomenography - A research approach investigating different understandings of reality. Journal of Thought 21(3, autumn): 28-49.

Mathner, N.-Doucet, A. 1997. Reflections on a voice-centered relational method: Analysing maternal and domestic voices. In: R. J.-R. Edwards (eds), Feminist dilemmas in qualitative research: Public knowledge and private lives. London: Sage. 119-146.

Mayring, Philipp 2000. Qualitative content analysis. Forum: Qualitative Social Research 1(2): art. 20. http://www.qualitative-research.net/fqs-texte/2-00/200mayring-e.htm.

McDonald, Lex. 2012. Educational transfer to developing countries: Policy and skill facilitation. Procedia - Social and Behavioural Sciences 69: 1817-1826.

Mykoff, N. 2012. Liberal arts in the Netherlands: Transplanted and transformed. In: Herman Tak-Barbara Oomen (eds), De disciplines voorbij. De colleges van Hans Adriaansens. Roosevelt Academy Middleburg. 61-69.

Pang, M. 1999. Two faces of variation: On continuity in the phenomenographic movement. Paper presented at the $8^{\text {th }}$ Biennial Conference of the European Association for Research in Learning and Instruction, Gothenburg.

Perry, L. B.-Tor, G. 2008. Understanding educational transfer: Theoretical perspectives and conceptual frameworks. Prospects 38: 509-526. 
Phillips, D.-Ochs, K. 2004. Researching policy borrowing: Some methodological challenges in comparative education. British Educational Research Journal 30(6): 773-784.

Rappleye, J.-Imoto, Y.-Horiguchi, S. 2011. Towards 'thick description' of educational transfer: Understanding a Japanese institution's 'import' of European language policy. Comparative Education 47(4): 411-432.

Santiago, Paulo et al. 2012. Education system evaluation. In: OECD Reviews of Evaluation and Assessment in Education: Czech Republic. OECD Publishing. https://doi.org/10.1787/9789264116788-en.

Stefon, M. 2016. Ren. Encyclopaedia Britannica. Retrieved from: https://www. britannica.com/topic/ren.

Steiner-Khamsi, G. (ed.). 2004. The global politics of educational borrowing and lending. Teachers College, Columbia University.

Swidler Ann. 1986. Culture in action: Symbols and strategies. American Sociological Review 51: 273-86.

Thornton, P.-Ocasio, W.-Lounsbury, M. 2012. The institutional logics perspective. A new approach to culture, structure, and process. United Kingdom: Oxford University Press.

Trist, E. 1980. The environment and systems response capability: A futures perspective. Futures 9(4): 113-127.

Wang, W. 2014. The Yuanpei Program in Peking University. A case study of curriculum innovation. Berlin-Heidelberg: Springer.

Zhou, P. Y. 1981. Reflections after a visit to America: Issues of Chinese higher education reform [Fangmei Yougan: Guanyu Gaodeng Jiaoyu Gaige De Jige Wenti]. People's Daily: p. 3.

XXXX (The disciples of) Confucius. The Analects of Confucius 6(30). Retrieved from: http://ctext.org/analects/yong-ye/zh?en=on. 